\title{
LITERATURA DA PERESTROIKA OU PERESTROIKA NA LITERATURA? (O conto russo dos anos 80 )
}

\author{
Elena Godoy ${ }^{\star}$
}

"A missão do homem russo è incontestavelmente européia e mundial. Ser e tornar-se um vendadeiro russo talvez signifique, em última análise, ser e tornar-se irmão de todos os homens.

F. Dostoievski

ara entender o conto russo dos anos 80 , é necessário que se conheçam os valores nele presentes. O fato é que freqüentemente esse conto traz afirmações e reflexões que o leitor ocidental poderia considerar evidentes. Assim, poderiam parecer evidentes, e até banais, $\propto$ temas e as afirmações existenciais, dos quais a literatura européia e americana deste século deu amplo testemunho. Entretanto, no contexto da literatura russa, esses temas e essas afirmaçōes assumem um caráter particular. Para que se entenda melhor esse contexto, optamos aqui por uma espécie de "dupla perspectiva”, mostrando ao leitor o panorama literário russo dos dois "degelos" políticos e culturais: o dos anos 60 e o dos anos 80 .

* Universidade Federal do Paraná. 
Desde a revolução de 1917 , a escola literária oficial na URSS era o chamado realismo socialista, uma das inevitáveis conseqüências do totalitarismo político. A definição dessa escola se reduz a uma frase pronunciada por um eminente teórico no $2^{2}$ Congresso de Escritores Soviéticos em 1954: "O realismo socialista, método fundamental da literatura e da crítica soviéticas, requer do artista uma representação verídica e historicamente concreta da realidade em seu desenvolvimento revolucionário".' A fórmula traduz o desejo dos velhos dirigentes do Partido Comunista de ver a literatura cumprir suas funções utilitárias, adotando uma espécie de ascetismo artistico: o realismo socialista proscreve o fator prazer tanto na contemplação prazerosa como no juízo prazeroso. $\mathrm{O}$ artista e o crítico comunistas interpretam as imagens e as personagens como armas de ação direta, que servem para mudar o mundo. São considerados inúteis os problemas de interesse metafísico, religioso ou humanistico e, com isso, eliminada uma grande quantidade de temas tratados pelos clássicos russos e pela literatura ocidental. Ao definir o Novo Herói como um indivíduo essencialmente positivo e de ação, condicionado pelo meio social e econômico soviético, os doutrinários conservadores descartam a exploração das complexidades psicológicas do homem, seus instintos, paixões e impulsos subconscientes. Os teóricos do Partido proclamavam que os juizos morais e sociais (de uma classe) são o único critério dos valores estéticos. Com isso, era proibido o absurdo, a imaginacão e quaisquer "manifestações desrespeitosas", o que explica o indigesto da maior parte da produção literária soviética. “A nossa literatura da época de Stalin - diz um crítico soviético anônimo, - estava tão cheia do vaporoso algodão de otimismo, de heroísmo, de falta de conflitos, dos lemas da propaganda oficial e de patriotismo, que seus protagonistas pareciam ser o dobro do tamanho natural e eram como as figuras de cera de Mme.Tussaud". 2

É importante lembrar que, apesar de todos os ziguezagues políticos, o grupo dirigente do Partido Comunista nunca renunciou ao controle da arte e de toda a vida cultural da URSS. Ao assumir a presidência do Partido em 1956, Nikita Khrushchev teve que encarar um sério problema: como preservar a coesão do Partido e a integridade da doutrina, declarando ao mesmo tempo criminoso o homem que tinha dominado esse Partido e o pais durante vinte anos? $\mathrm{Na}$ literatura se colocava a questão semelhante: como preservar a estética do Partido, defender a teoria do realismo socialista, condenando ao mesmo tempo os produtos dessas teorias e toda a prática baseada nessa estética?

1 SLONIM, M. Escritores y problemas de la literatura sovićtica 1917-1967. Madrid : Alianza, 1974, p. 374.

2 Idem, p. 363. 
Uma boa parte da literatura sovićtica ia se afastando dos moldes oficiais. As mudanças eram amplas e variadas: maior diversidade de estilo, mais imaginação nas tramas, mais liberdade na estrutura da narrativa e no uso da linguagem. Apareciam agora os temas tão perigosos como as tragédias pessoais provocadas pelo terror stalinista. A partir de 1955-56, os romances russos se povoaram de comunistas inocentes que tinham sido condenados a anos e anos de trabalhos forçados nos campos do GULAG, de patriotas não afiliados ao Partido que voltavam do exílio e de filhas e filhos cujos pais foram levados pela KGB para sempre numa noite.

O movimento geral para uma representação crítica da vida foi uma reação contra as falsidades laudatórias e o "envemizado" da realidade. Os escritores competiam entre si na exposição dos defeitos do sistema. Havia uma inquietude, um sentimento de descontentamento, uma atitude critica diante da sociedade, um interesse cada vez maior pelas idéias novas, uma não aceitação de fórmulas enferrujadas. Foi um momento curioso: enquanto os pais estavam do lado dos stalinistas conservadores, seus filhos apoiavam a reforma política e a vanguarda artística. Da geração dos "lillhos" são E. Evtushenko, A. Voznesenski, A. Solzhenitsin, entre outros.

No entanto, um mês depois da publicação de Um dia de Ivan Denisovitch de Solzhenitsin, acontecimento esse que alegrou aos liberais, 0 "degelo" cultural foi seguido de um novo "congelamento". Em dezembro de 1962, Khrushchev, depois de visitar em Moscou uma exposição de pinturas e esculturas qualificadas por ele de "abstratas" (erroneamente: em termos ocidentais, a exposição poderia ter sido chamada de simplesmente "pós-expressionista"), lançou uma violenta campanha contra os modernismos nas artes. Por trás dessa restauração da “linha dura" e do realismo socialista estavam - incentivados pela crise cubana - os conservadores que, temendo que o "abrandamento" e as concessões aos liberais scriam interpretados pelos inimigos como uma derrota ideológica após uma derrota politica, consideraram necessária uma reafinnação da integridade doutrinária e o ajuste do controle do Partido. A campanha que começou com as artes plásticas logo se estendeu à literatura. Em agosto de 1963, durante a reunião da União Européia de Escritores, em Leningrado, os oradores oficiais sovićticos exaltaram o realismo socialista como a única "tendència literária fecunda" $\mathrm{e}$ repeliram Joyce, Proust e Kafka, considerando-os "formalistas burgueses decadentes".

Em 1965, dois escritores - Andrei Siniavski e Yuli Danicl - foram detidos em Moscou e acusados de ter publicado suas obras no exterior. Siniavski era muito conhecido como um bom escritor, como um crítico literário c o autor de livros sobre Picasso e sobre a poesia soviética da decada de 20 . Tinha escrito também uma introdução a um livro de poesias de B. Pasternak. Num ensaio 
sobre o realismo socialista, Siniavski formulava assim seu credo literário: "Agora mesmo coloco as minhas espcranças numa arte fantasmagórica, com hipóteses em vez de propósitos, uma arte em que o grotesco substitua a descrição realista da vida do dia-a-dia. Unna arte assim corresponderia melhor ao espirito do nosso tempo. Oxalá a imaginação fantística de Holfmann e Dostoievski, de Goya, Chagall e Maiakovski... nos ensine a sernos verdadeiros com a ajuda do absurdo e do imaginário". ${ }^{3}$ Daniel era um excelente tradutor, bom conhecedor da literatura ocidental. Ambos pertenciam à nova geração de intelectuais soviéticos e sua detençāo foi interpretada pelos liberais como um golpe. Durante o processo dos dois escritores não foi permitida a presença de jornalistas estrangeiros na sala do tribunal. Siniavski foi condenado a sete anos de trabalhos forçados num "campo de regime severo", e Daniel a cinco. A severidade da sentença teve um único motivo: servir de advertência aos intelectuais russos e reafirmar a linha dura na literatura. É evidente que Siniavski e Daniel não foram os únicos e que houve muitos outros escritores talentosos, cujas obras são ainda desconhecidas no scu pais. Os manuscritos de algumas dessas obras circularam clandestinamente pelas cidades russas. Alguns outros manuscritos passaram "de contrabando" ao exterior. A descoberta desses contos, romances e poemas está acontecendo e vai acontecer ainda durante alguns anos.

Assim, após o "degelo" cultural dos anos 60 , o horizonte literário russo se vê fechado de novo. Eé nesse momento que começa a tomar forma um novo mundo de expressão. $O$ número sempre crescente de "revistas grossas" clandestinas (Sintaxis, Fénix, Esfinge, etc.) capazes de encontrar e abrigar novos talentos se torna uma autentica expressão cultural. As "revistas grossas" literárias são uma tradição na Rússia desde o século XVIIl. A revista ocidental, nas suas páginas, abre o espaço para as obras literárias, mas principalmente se dedica às discussões críticas e teóricas. As dimensões dessas obras são limitadas: se trata de poemas e contos breves e dificilmente encontrariamos romances nas páginas dessas revistas.

A tradição russa, ao contrário, concebeu a revista como um caminho normal (e rápido) para a publicaçāo de obras literírias. A "revista grossa" russa pode levar aos seus leitores um romance extenso em apenas dois ou três números. Com isso, a revista deixa de ser o espaço dedicado exclusivamente à rellexão crítica e se torna tambćm o lugar do primeiro encontro do leitor com o texto literário. As "revistas grossas" de hoje (Novy Mir, Neva, Oktiabr, Iunost e outras) conservam essa característica. 
Os iniciadores dessa nova tendencia litcrária sovićtica recorrem às experiências adquiridas já há tempo no Ocidente. Mas não porlemos esquecer que a Rússia, um pais que estava na vanguarda curopéia nos anos $10 \mathrm{e} 20$, se encontra agora no ponto de partida devido à grande falta de comunicaçào com o mundo exterior durante os últimos quarenta anos.

Os cinco anos da "perestroika” foram uma espécic do segundo “degelo" na literatura. Foi a festa da embriaguez da "glasnost", da riqueza da literatura "detida" (assim se chamava a literatura censurada e não publicada na Rússia) e da literatura dos emigrantes. Mas a descoberta dessas obras também não foi fícil. Assim, só graças a uma forte pressĩo -de baixo" foi possivel a publicação do Arquipélago GULAG de Solzhenitsin e depois do resto de sua prosa.

Muitos nāo aceitavam os principios humanistas gerais do "ocidental" $A$. Sakharov, outros não entendiam a inclinação de A. Solzhenitsin à hiperbolização das peculiaridades russas, sua acusação da própria Revolução de Outubro (c não só de alguns dirigentes "mal-intencionados") pelas desgraças do pais e sua religiosidade. Na realidade, era a fusino de duas fontes, o aperto de duas mãos, mesimo quando os dois líderes intelectuais levantavam uma intensa polémica nos encontros pessoais e nos artigos de jornais.

Durante o primeiro “degclo", renasceu na Rússia o conceito de humanismo, aquele que nĩo se divide em "abstrato", ou "ocidental", e socialista, mas que se baseia na confiança no ser humano e na fé no homem. O conceito de "pathos humanista", que surgiu naquele momento, encarnou o interesse pelo ser humano como criatura válida em si mesma e nāo como um parafuso da enorine máquina do Estado, uma criatura válida pela sua consciència, pelos seus sentimentos e dúvidas e não pela sua fidelidade aos dogmas impostos. No mesmo moinento surgiu uma espécie de dualidade da busca do ser humano: o que acontece dentro do homem e o que the é ditado de fora. O homem que busca era contraposto ao homem que cumpre, aquele formado pelo sistema totalitário.

Nos anos da perestroika, as idćias do humanismo já levaram à prioridade dos valores humanos sobre os de uma classe ao reconhecimento oficial, estatal e partidário. Para isso contribuiu, e em muito, a avalanche da litcratura ocidental e da dos emigrantes russos. O ensaio geral foi o primeiro "degelo", com as publicaçōess de alguns livros de Heıningway, Remark, Salinger e dos livros de alguns emigrantes e os "detidos": a prosa de I. Bunin, Margarita e o Mestre de M. Bulgakov. Essas publicaçōes prepararam a futura entrada (já no final dos anos 70) do romance psicológico ocidental e do romance fantístico latino-americano. E cada vez a resistência contra essa literatura era encabeçada pelos "laureados" e canonizados criadoris das sagas em muitos volumes sobre os heróis do trabalho socialista e os cavalheiros da Estrela de Ouro da guerra. Naquele periodo, os escritores tentavam entender o que aconleceu alinal, o que 
está acontecendo no pais e nas almas humanas: tudo era novo, até o próprio conceito do culto da personalidade. Agora, aqueles insights se tornaram antológicos, e no lugar do culto da personalidade se descortinaram o gélido regime totalitário e o genocidio do próprio povo. À literatura só restou ilustrar aquilo que se tomou do conhecimento de todos através dos meios de comunicação. Para a consciência pública, esse poço já estava seco.

Como era de esperar, durante os dois "degelos", aparecem no palco os jovens. Na década de 60 se levantou a "segunda onda" da prosa de gucrra (Iu. Kazakov). Agora chamam a atenção S. Kaledin com seu Cemitério resignado e Va.Pietsukh com seus contos e a Nova filosofia moscovita. A prosa “da confissão" anterior com seu herói da alma pura e cristalina é trocada agora pela exploração das obscuras profundidades da natureza humana. $O$ horror e a crueldade fazem a sua festa na literatura de hoje, como em $O$ ar da liberdade de L. Petrushevskaia. O erótico, antes proibido, está em alta nos contos de V. Narbikova e V. Ierofeev.

A ironia quase ausente na literatura dos anos 60, com as exceçōes de B. Aksenov e V. Voinovitch, hoje está presente em praticamente todas as obras. Se no momento anterior essa era a ironia do vencedor, o risinho do mais forte, agora esta ironia é provocada pela alienação, pelo afastamento do ser humano dos acontecimentos, é o "sorriso amargo do filho enganado pelo pai falido". Alguns críticos russos consideram a ironia como um traço forte do antes clandestino $\mathrm{e}$ agora livre underground.

Nos tempos da estagnação nasceram - e agora, nos tempos da perestroika, cresceram - a alusão, a reticência, o deslocamento surrealista, o largo uso da intertextualidade. $O$ principal gênero literário voltou a scr o conto, que permite ao contista se sentir livre da obrigação de construir um quadro da vida conceitualmente refletido (que tradicionalmente é uma das caracteristicas do romance russo). O que apresenta o conto russo da época da perestroika são fragmentos: da vida, das pessoas, dos sentimentos, das recordaçōes, das esperanças...

Já no momento do primeiro "degelo", a literatura russa fez tentativas de se libertar dos cânones do realismo socialista, da conformidade de idéias. Surgem assim - timidamente ainda o "realismo fantístico" de A. Siniavski, o "mitologismo" de Tch. Aitmatov, a prosa irônico-filosófica de alguns outros jovens. Mas, contudo, essa prosa, sendo nova pelas suas idéias, continuava fiel aos princípios da tradicional "veracidade" realista. Era uma literatura marcada pelo otimismo, pelo cntusiasmo, pela energia da geração dos combatentes de guerra. O que caracteriza a litcratura dos anos 80 é o pessimismo, o choque, a angústia c a perturbação. Ė a perturbação diante da avalanche da glasnost, diante do caos total da economia, diante da transformação dos cultos religiosos num fenômeno de cultura de massa, diante do abismo apocalíptico aberto, diante, 
enfim, da tentação diabólica de reduzir tudo isso à visão de um vidro fechado com as aranhas revolucionárias se devorando dentro...

Mas o que parece ser a diferença mais forte entre os dois "degelos" é que durante o primeiro praticamente não existiu a idéia do "espirito nacional", da auto-suliciência da arte russa. Era muito forte a crença nas ripidas e benélicas transformaçōes sociais e eticas. Agora que exsa crença morreu sem deixar herdeiros, os escritores russos buscam os princípios verdadeiranente nacionais, as tradições nacionais transistóricas.

Junto com esse "espírito nacional" cresce espantosatmente a inclinação à religiosidade, absoluta $\mathrm{e}$ incondicionalmente proibida durante os setenta anos do regime soviético: "É impossível entender a história da Rússia sem a história da Igreja Ortodoxa" - diz un crílico russo. ${ }^{4}$ Justamente no renascimento da religiosidade, muitos escritores vècm o único caminho para os principios éticos lirmes: -Estou convencido que é impossivel levantar ou fazer renascer a sociedade russa sem apelar às bases da ética crista” e "os melhores escritores são, via de regra, pessoas religiosas ou próximas da cultura crista” - alinna outro crítico. ${ }^{5}$

Recapitulamos aqui, muito brevemente, os últimos trinta anos da literatura russa para que se possa entender um pouco melhor o contexto particular dessa litcratura. Parece claro que a litcratura da Rússia, como o próprio país, está procurando seu caminho.

\section{RESUMO}

O trabatho tem como lïnalidade examinar o contexto da produção literária russa dos anos 80 à luz dos dois "degelos" políticos e culturais: o dos anos 60 e o da "perestroika".

Palav'as-chave: Literatura russa, Literaura comemporânea, História da literotura russa.

4 KRUPIN, V. Literaturnaia Rossia, 06.05. 1989

5 SIDOROV. le. Inostrammaia literatura, 11, 1990, p. 211 


\section{RESUMEN}

El objetivo de este trabajo es examinar el contexto de la producción literaria rusa de los años 80 a la luz de los dos "deshielos" políticos y culturales: el de los años 60 y el de la "perestroyka".

\section{REFERÊNCIAS BIBLIOGRÁFICAS}

KRUPIN, V. Literaturnaia Rossia, 06.05.1989

SIDOROV, Ie. Inostrannaia literatura 11, 1990.

SLONIM, M. Escritores y problemas de la literatura soviética, 1917-1960. Madrid : Alianza, 1974. 